\title{
A Review Paper on Sustainable Cost Effective Concrete for Corrosive Environment
}

\author{
R. Darwin ${ }^{* a} \quad$ S. Usha ${ }^{* *}$ \\ Department of Civil Engineering \\ Mepco Schlenk Engineering College, Sivakasi, Tamil Nadu, India
}

\begin{abstract}
For its favorable properties and easily availability, the use of concrete increasing annually. When the concrete exposed to environment it start to disintegrate due to chemical attack. The chemical attacks on concrete majorly are in the form of a reaction between aggressive agents and the cement matrix, although reactions can also happen with the aggregates. This review paper gives a suggestion to make a cost effective and durable concrete to perform well in the aggressive corrosion environment by the waste products obtained from different industry. The use of Portland cement concrete has an impact on the environmental due to the emission of $\mathrm{CO}_{2}$ in the atmosphere. On the other side handling of plastic waste was a major problem all over the world. So, as to give suggestion to these problems the study has been made as the use of rice husk ash (obtained from agricultural waste) and silica fume (obtained from alloy industry) as partial replacement of Portland cement to increase strength at early and later ages. And due to its micro structure it reduce the permeability of concrete and exhibit considerable enhancement in durability, also provides better bond between cement matrix and the aggregate. The usage of LDPE is high throughout the world compared to other plastics, the density of LDPE range from 925$940 \mathrm{~kg} / \mathrm{m}^{3}$ so the density of the concrete greatly reduce up to $30 \%$ as their wastes can be used as a replacement for fine aggregate.. In terms of durability the high amount of silica impregnated the concrete samples and thereby reduces porosity of concrete. The strength reduction due to plastics will nearly compensated by the RHA and $\mathrm{SF}$. The use of such waste products gives cost effective and reducing $\mathrm{co}_{2}$ emission and best method for the disposal of plastic wastes.
\end{abstract}

Keywords: Silica Fume, Rice husk ash, LDPE, Durability

DOI: $10.7176 / \mathrm{CER} / 11-5-05$

Publication date:June $30^{\text {th }} 2019$

\section{Introduction \\ Cement Concrete}

Cement concrete is most used material next to water in the earth, because of its economy, ability to be mould to any shape, ability to be fabricated and durability has become popular over the century [1]. Now a day's problem in manufacturing of concrete mainly depends on two materials one is cement due to its emission of $\mathrm{CO}_{2}$ and another one is fine aggregate due to its scarcity, which plays a major roles in the cost for production of concrete, the mechanical behavior of concrete and the durability of concrete. Cement is an adhesive material used in concrete construction that sets, hardens, and bond them together. Cement is used on its own, but rather to bind sand and gravel (aggregate) together. Cement mixed with fine aggregate produces mortar for masonry, or with sand and gravel, produces cement concrete. For cement manufacturing, it consumes a lot of natural resource to generate the necessary energy for cement production. Nearly $130 \mathrm{~kg}$ of fuel and $110 \mathrm{KWh}$ of electricity required for production of each tonne of OPC, which emits around 0.9 tonne of $\mathrm{CO}_{2}$. About $6 \%$ of man-made carbon emission is due to production of OPC. As on date the annual production of OPC is around 3.6 billion metric tonnes and by 2030, it may raise up to 5 billion metric tonne [1]. As long as the need of concrete the need of cement gets increased every year, while in the manufacturing of cement huge amounts of carbon dioxide $\left(\mathrm{CO}_{2}\right)$ are released [1].

\begin{abstract}
Admixtures
Alternative sustainable materials for cement in order to minimize the $\mathrm{CO}_{2}$ emission, materials obtained from industrial wastes are used as a sustainable replacement for cement. Some of these products can be used in the manufacturing of concrete and termed as 'mineral admixtures'. These are fillers that can react to form compounds having similar properties as of cement which can be obtained as a waste by product in many forms [4]. To make concrete a cost effective and sustainable material the use of agro waste ash as a replacement for cement content to improve the durability of concrete, various types of agro waste ashes are Rice husk ash, Bagasse ash, palm ash. Agro waste ashes have pozzolanic properties in which formless silica combined with lime and forms as binding material [3].
\end{abstract}

\section{Rice husk ash}

Burning of rice husk at controlled burning temperatures below $700^{\circ} \mathrm{C}$, formless silica in $\mathrm{RHA}$ is formed which is 
very reactive by nature. The result showed that the highest amount of formless silica occur in rice husk burnt in the range of $500-700^{\circ} \mathrm{C}$. The properly burnt ground rice husk can be used as a mineral admixture in the production of cement, and the behavior of the adhesive products varies with the source of RHA. High amounts (up to $30 \%$ ) of RHA could be blended with cement without adversely affecting the mechanical (strength) and durability (permeability) of concrete. For durability, RHA often improves the concrete's resistance to deterioration from sulphate and chlorides, and also lowers the temperature of fresh concrete [3]. RHA, as a partial replacement for cement could contribute to a series of advantagesous performances by demonstrating economical, environmental, and technical advantages because it provides a new use for waste materials, produces cheaper concrete for low cost construction, and reduce of carbon emissions. The utilization of RHA as a pozzolanic material in cement and concrete provides several advantages, such as improved strength and durability properties, reduced materials cost due to cement savings, and environmental benefits related to the disposal of waste materials [5]. The effectiveness of rice husk ash to serve as a pozzolan in Portland cement concrete is primarily dependent on its silica content and the nature of silica present in RHA. For instance, the concretes containing RHA with high amorphous silica content showed higher compressive strength and lower permeability than those RHAs containing crystalline silica [5]. This may be because the high amount of amorphous silica in RHA attributes to quicker depletion of calcium hydroxide especially at early ages, thereby in result enhanced strength and reduced Permeability, and several investigations suggest the beneficial use of lowcarbon RHA with amorphous silica to significantly improve specific durability property of Portland cement concrete [5]. Ehsan Mohseni et al. 2015 conducted experiments on metakaolin (MK) and rice husk ash (RHA) as a partial replacement material for cement, and polypropylene (PP) as an additive, on the mechanical and water absorption properties of mortar, and reported that increasing in the compressive strength of about $13 \%$. Also stated that the increasing of RHA more than $20 \%$ leads to increase in water absorption. [12]. A.Muthadhi and S.Kothandaraman also reported that the incorporation of RHA increases compressive strength up to $30 \%$ and the peak value attain at $20 \%$ replacement levels. The maximum reduction in water absorption was achieved for $30 \%$ RHA addition [13]. ravande kishore et al. 2011 tested for both M40 and M50 grade mix at different percentage of RHA and reported that the increase of RHA, the decrease in workability and compaction by $27 \%$ and $9 \%$ respectively. For the replacement levels with later ages performs wells. The optimum replacement level of Rice Husk Ash is found to be to10\% for both M40 and M50 grades of concrete [18]. Samuel Kofi Tulashie et al. 2017 also reports that the highest compressive strength of cement mortar prisms was achieved at $11.11 \%$ rice husk additive, indicating $8.4 \%$ and $21.2 \%$ rise on the $7^{\text {th }}$ and 28 th day. Conversely, $22.22 \%$ rice husk ash addition also showed significant improvement $(12 \%$ and $17.3 \%)$ in the compressive strength [19].

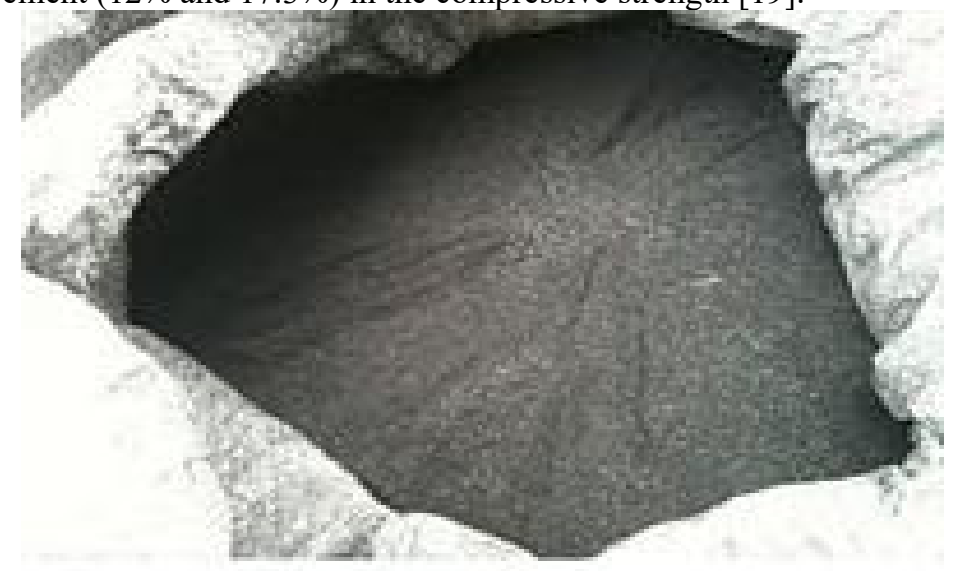

Fig1. Rice Husk Ash

\section{Silica Fume}

Silica fume (SF) is a byproduct obtained after the smelting process in the silicon and ferrosilicon industry. It is also known as micro silica or silica dust. The reduction of high-purity quartz to silicon at temperatures up to 2,000C produces $\mathrm{SiO} 2$ vapours, which oxidizes and condense in the low temperature zone to tiny particles consisting of non-crystalline silica. By-products of the production of silicon metal and the ferrosilicon alloys having silicon contents of $75 \%$ or more contain $85-95 \%$ non-crystalline micro silica. The by-product of the production of ferrosilicon alloy having 50\% silicon has lower silica content and is less pozzolanic [6]. The American concrete institute (ACI) defines silica fume as a "very fine non crystalline silica produced in electric arc furnaces as a byproduct of production of elemental silicon or alloys containing silicon'. It is usually in the form of grey colored powder, somewhat similar to Portland cement or fly ashes. It can exhibit both pozzolanic and cementitious properties [6]. Because of its extreme fineness and high amorphous silica content, it enhances 
the pozzolanic reaction by reacting with calcium hydroxide resulting from primary hydration [7]. Silica fume has been recognized as a pozzolanic admixture that is effectively enhancing the mechanical properties to a great extent. By using silica fume along with superplasticizers, it is easier to obtain compressive strengths [6]. Addition of silica fume to concrete improves the durability of concrete due to reduction in the permeability, refined pore structure, leading to a reduction in the diffusion of harmful ions, reduces calcium hydroxide content which significantly results in a higher resistance to sulfate attack [6]. Safwan A.khedr et al. 2014 reported that the addition of silica fume about $15-20 \%$ gives maximum strength over control specimen; also the use of super plasticizer is preferred for increase in silica fume. The sample containing micro silica shows better results in acid attack than control specimen [14].

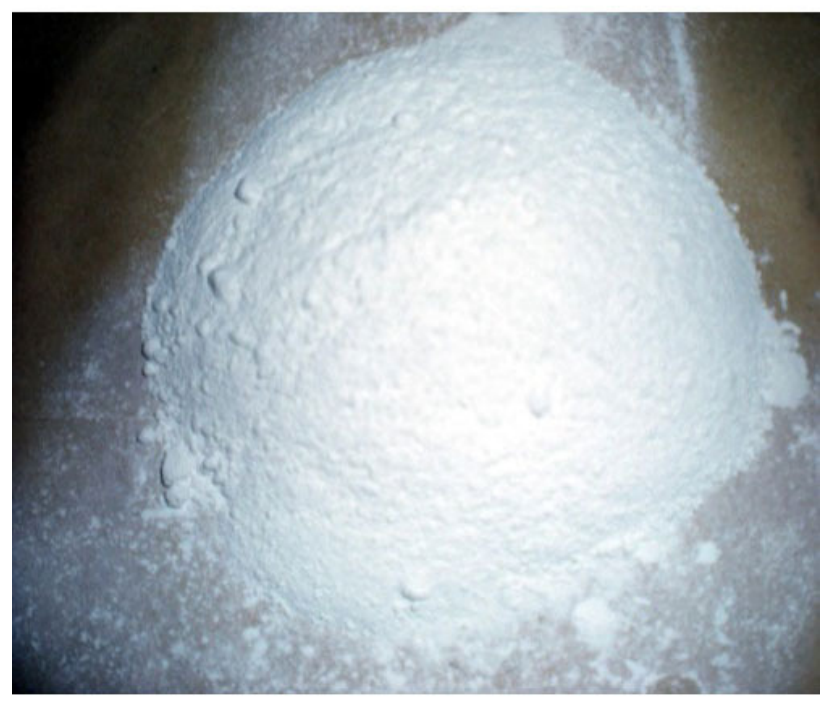

Fig2. Silica Fume

\section{Plastic (LDPE)}

Also Environmental impact of dredging, excavating and processing natural aggregate such as threat to river ecosystems, As a result of these environmental concerns, authorities in some parts of the world have imposed restrictions on mining of aggregate through taxation as well as banning of mining on some sites. Environmentalism is a basic principle of sustainable development which aims at protecting the environment and conserving the earth's natural resources [11]. Trends in concrete technology are currently directed towards sourcing alternative sustainable materials for concrete in order to minimize over-reliance on natural resources. Many of the substitute materials used for producing green concrete are recycled materials obtained from industrial wastes and by-products [11]. Plastic is one of the most relevant innovations of the twenty first century. This material has been widely used as a raw material in the manufacture of packaging, electrical and household appliances, toys and various other goods. Total plastic consumption has been increasing in recent years and so contributing to growing volume in the plastic waste stream. This is considered a serious environmental threat, especially in Asia [8]. The use of plastic waste as a substitute for natural aggregate in concrete is a relatively recent concept. One of the first significant reviews on the use of waste plastic in concrete focused on the advantages and economical benefits of such use, besides their physical and mechanical properties. There was common base in that the use of plastic waste aggregate is viable, even though the performance of most properties declined [8]. The plastic wastes can beneficially be incorporated in concrete, as fine aggregates or as supplementary cementitious materials, it is important to notice that not all type of material's wastes are suitable for such use, A decrease in slump value with increase in PET waste as partial aggregate replacement. At $20 \%$ replacement the slump decreasing by 20-58 $\mathrm{mm}$ [9]. F.S. Khalid et al. 2018 used the plastic wastes as manufactured synthetic macro-fibers in $\mathrm{RC}$ beams, which show the better behavior in cracking stage, concrete beams containing $10 \%$ plastic fibers showed that the strength of the first crack improved by $32.3 \%$ compared to normal concrete beams [17]. Brahim Safi et al. 2013 stated that Reduction in the compressive strength was between $15 \%$ and $33 \%$ for mortar containing $20-50 \%$ plastic waste, and the mortar containing up to $50 \%$ of plastic waste was acceptable for lightweight mortars with the bulk density $1.5 \mathrm{~kg} / \mathrm{m}^{3}$ [21]. Two major products of the plastic industries are low-density polyethylene (LDPE) and high-density polyethylene (HDPE). HDPE is stiffer, higher in tensile strength, and better in heat resistance, whereas LDPE is more flexible, both of them are low density ranging from $925-940 \mathrm{~kg} / \mathrm{m}^{3}$ [16]. Alternative fine aggregate material such as quarry dust, sludge waste or in the form of ash along with waste plastic in concrete can be a potential application for mass 
concreting works in order to reduce the river sand depletion. Further it can be concluded that the utilization of dust along with waste plastics leads to ecofriendly and economic construction due to LDPE is partly crystalline and partly amorphous structure due to the existence of sharp narrow [10]. Fahad K. Alqahtani et al.2016 developed the recycled plastic aggregate (RPA), and used as a replacement for coarse aggregate. The loss in compressive and flexure strength is of about $40 \%$ and $20 \%$ respectively. The LDPE and LLDPE are used in the manufacture of RPA; both of them are recyclable wastes which reduce the $\mathrm{co}_{2}$ emission. Also the dead weight of the structure is greatly reduced. [15]. Rafat Siddique et al.2008 reviewed many journals and stated that the use of the recycled plastic in the concrete reduced the overall concrete bulk density. The bulk density was reduced by $2.5-13 \%$ for concrete which contain plastic aggregates ranging from $10 \%$ to $50 \%$. And reduction in the compressive strength was between $34 \%$ and $67 \%$ for concrete containing $10-50 \%$. There is a reduction in the abrasion of concrete containing recycle plastics then control mix. Also gives better results in impact resistance of recycled plastic concrete [22].

\section{Durability}

Now a day's concrete is a factory made and hence it has high efficiency by avoiding on site errors Major problem in concrete is its performance in durability under long term behaviour exposed to outside environment, The majority of chemical attacks on concrete are in the form of a reaction between aggressive agents and the cement matrix, although reactions can also happen with the aggregate. Durability of cement concrete is defined as its ability to resist weathering action, chemical attack, abrasion, or any other process of deterioration to remain its original form, quality and serviceability when exposed to its intended service environment. Although in recent years, the decline in quality of concrete wearing surfaces has become a major problem. This decline in quality takes in many forms, among which are scaling, ravelings, abrasion, spalling, pitting and cracking.

Degradation of concrete strength due to sulphate attack takes place when the calcium and hydroxide ions dissolve out of the matrix, causing an increase in porosity and permeability of the concrete surface. Durability of concrete strongly affects the service life of structural members. Durable concrete protects embedded reinforcing steel from corrosion and reduces the potential for concrete spalling under chemical attack [2]. The durability of building materials is related to the presence of cracks as they provide a fast pathway for penetrate of liquid and gases through the structure. For restoration and preservation the technique which uses nano-silica and silica fume particles for consolidation. The small particle size range and the high reactivity of nanoparticles allow them to interact with calcium sources naturally present in cement and concrete, forming binding and strengthening, also act as a crack-filling agent, reducing the porosity and thereby increasing the durability of existing materials [20]. Riccardo Maddalena andAndrea Hamilton (2017) stted that Silica injection has effectively impregnated cement samples, after 14 days of injection with a nanosilica a total reduction of $30 \%$ in porosity was observed, and Some of the silica injected has reacted with the calcium hydroxide naturally present in hydrated cement, forming additional binding phases such as C-S-H and C-A-S-H. Unreacted silica has been absorbed and acts as a filler agent reducing porosity [20].

\section{Discussion}

A.Muthadhi and S.Kothandaraman conducted an experimental investigation on incorporation of RHA on concrete to enhance the mechanical and durability performance; they have replaced the RHA in the ratio of $10 \%$, $20 \%$ and $30 \%$ with the mass of cement content. They have been investigated properties include of compressive strength, chloride permeability, water absorption, and sorptivity of RHA blended concrete. The ash was finely ground in a ball mill until the average particle size was less than $45 \mu \mathrm{m}$, as long as the particle was finer which behave better in mechanical and durability aspects. In total, 228 concrete cube specimens including control mixtures are considered in this paper. Also, 224 cylindrical specimens of 100-mm diameter 50-mm depth were cast for the rapid chloride permeability and sorptivity test, and 96 cube specimens $(100 \times 100 \mathrm{~mm}$ size $)$ were cast for the water absorption test. And the super plasticizers' dosage was adjusted in each mixture to achieve a slump in the range of 75 to $100 \mathrm{~mm}$. The RHA addition has contributed to strength improvement of concrete at all ages. However, with the amount of cement replacement up to $20 \%$ with RHA, strength gain increases, and beyond this level of RHA addition the strength gain decreases. At the $30 \%$ RHA level, the compressive strength of RHA concrete attains values equivalent to those of control concrete mixtures. The rate of increase in compressive strength remains fairly uniform up to $10 \%$ of RHA level. Between 10 and $20 \%$ of RHA level, the rate of increase in compressive strength increases with an increase in RHA content. Maximum compressive strength is found at the $20 \%$. RHA improves compressive strength development in two ways apart from its pozzolanic activity. It accelerates the hydration process in the wet phase by providing more nucleation sites for the process to occur, while its pore-filling effect improves the packing characters of solid particles within the concrete matrix during later ages. The important parameter for the concrete to resist the corrosive environment is the closely packing of concrete micro structure so that the water cannot impregnated into the concrete, the RHA performs better in resistance of the of water absorption due to its closely packing of micro structure by nature. The water absorption 
values decrease with the percentage of replacement of RHA increases. The maximum reduction in water absorption was achieved at 30\% replacement. For the 30\% replacement of RHA by cement, the water absorption value reduced about 50\% compared to the control mix. At 28 and 90 days of curing, sorptivity progressively decreases with increases of RHA content up to 20\%. At 28 days, 20\% RHA addition yields significant reduction in sorptivity for all mixes. At 90 days of curing, the values are correspondingly lower for all mixes, indicating that up to 90 days can turn out to be beneficial. The $t$ reduction in sorptivity is primarily credited to the reduced porosity of the concretes at higher RHA content. At 30\% RHA addition, there is an increase in sorptivity, however, lower than that of control concrete. The maximum percentage of strength gain is achieved at $20 \%$ RHA. There is remarkable improvement in performance characteristics at $20 \%$ RHA addition, which is, approximately $57 \%$ of chloride permeability, $32 \%$ of water absorption, and $45 \%$ of sorptivity reduction compared to that of the reference mixture. When compared with the cost of cement. Rice Husk is a waste by product, the cost of production in the form of ash is lower than that of cement production. [23]
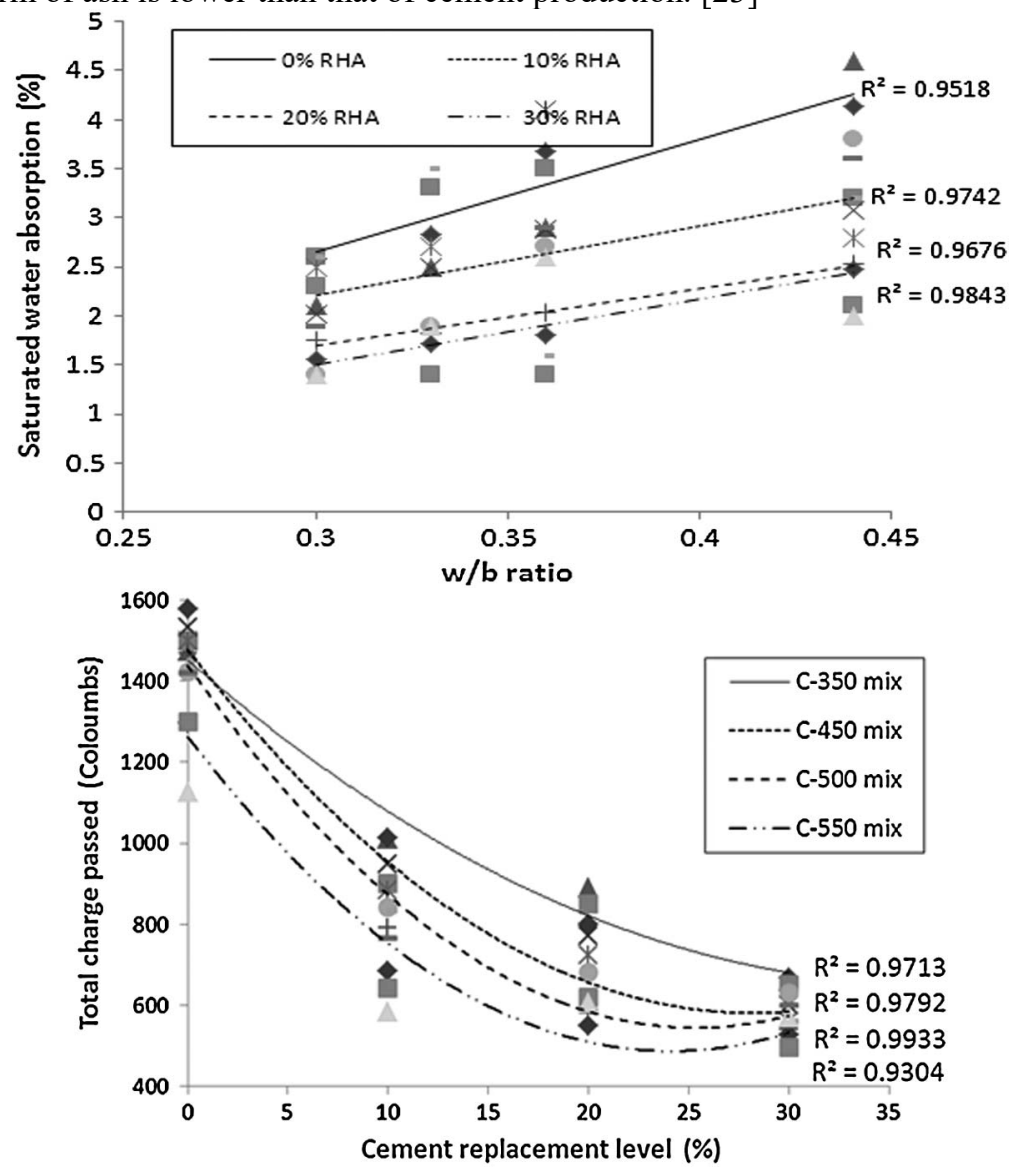

Nabajyoti Saikia and Jorge de Brito in his paper they reviewed form the previous works and discussed the types of plastics and types of methods used to prepare plastic aggregate as well as the methods of evaluation of various properties of aggregate and concrete were briefly discussed along with that various fresh and hardened concrete properties of cement mortar and concrete in presence of plastic aggregate are discussed. Majorly the use of plastic aggregate (flaky waste PET aggregate with two different size ranges and a pellet-shaped product) directly collected from waste PET treatment plant as aggregate in concrete. The two types of aggregates were obtained after mechanical grinding of PET waste. The washing of waste PET was done before and after grinding by using alkaline solutions. Stirring of ground PET in a clean water bath and centrifugation of grinded PET waste were also done to remove impurities. Modifications of plastic waste by heating, by mechanical means, by soaking in water, melting followed by mixing with other materials and other techniques were also done to improve the quality of plastic waste for using as aggregate in concrete. Choi et al prepared two types of plastic aggregates by mixing granulated pet waste bottle with powdered river sand and blast furnace slag at $250^{\circ} \mathrm{C}$ after air-cooling the mixtures, the prepared aggregates and remaining powdered fractions were screened by using a $0.15 \mathrm{~mm}$ sieve. When dealing with its slump value there is always a deviation in slump value with respect to the usage of different plastic as aggregate. To achieve a constant slump value, the concrete mix containing pellet plastic aggregate required a slightly lower w/c value and the concrete mixes containing the two flaky plastic aggregates with different particle size required much higher w/c values than that required by the concrete mix containing natural aggregate. When compared with the compressive, split tensile and flexural strength, there is a 
decrease in all types of mechanical strength with all types of replacement. With the $50 \%$ of replacement there is a decrease nearly $50 \%$ of strength on average of comparing the previous papers. But the main intention of adding the plastic waste is due to is durable in nature to resist in chemical and durable aspects. In abrasion resistance, with the replacement of fine aggregate by PET waste as aggregate increase the abrasion resistance of concrete or mortar in most of the stages with the replacement level of up to $10 \%$. The phenolphthalein solution was applied on the broken surfaces of the half pieces obtained after flexural-tensile strength test. The compositions of various mixes along with carbonation depth at various time periods are calculated. Irrespective of binder types, the carbonation depth of mortar containing only PET aggregate at or after 28 days of curing are lower than that of the mortar containing an aggregate mixture of PET and sand. Frigione measured the drying shrinkage property of one year cured concrete containing PET aggregate, which replaced 5\% in weight of fine natural aggregate. The author found an increase in drying shrinkage value due to the incorporation of PET aggregate in concrete for the different experimental conditions. Albano et al placed the cured slabs in a muffle furnace, the temperature inside the furnace was increased up to a pre-determined temperature, the slabs were kept at that temperature for 2 $\mathrm{h}$, and then heating was stopped immediately. The temperatures chosen for this study were $200 \_\mathrm{C}, 400$ C and 600 C. After cooling the specimen to room temperature, the flexural strength was determined. In parallel, unheated specimens were tested. Their results are indicated, as the temperature increased, the flexural strength decreased regardless of the level of substitution and the PET particle size. However, the decrease in flexural strength was more significant when the PET content was $20 \%$ due to the presence of more porosity (voids) [24].
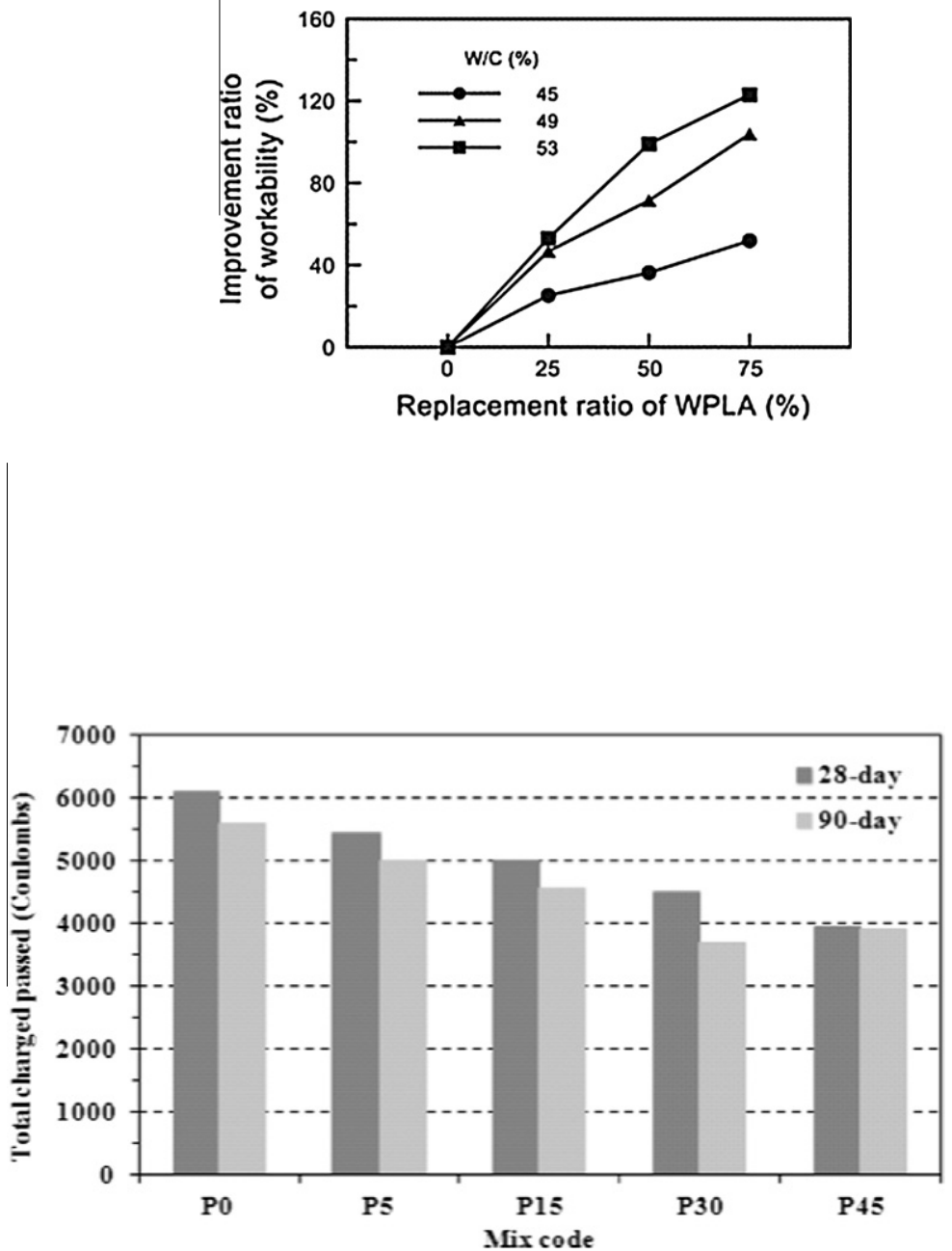

Research Significance

Environmental concerns due to the over-exploitation of sand have led to restrictions on extraction of sand all over the world, Thus, the construction industry has huge demand for a suitable environmentally friendly 
alternative to sand. On the other hand, recycling of waste plastic is rarely done in India, with nearly $40 \%$ left in landfill. The dumping of these plastic materials, which degrade at extremely low rates, will lead to high negative impacts in the society. On every year about 300 million tones of plastic was manufactured and it was roaming around the society, about $30 \%$ of them are single usage type plastics, about 80 million tones are dumped into the sea, and non reusable and non recyclable plastic are dumped in to the sand which affect the environment.

On using of plastic waste as a replacement for fine aggregate, a best way of maintaining the environment, an sustainable environment. Around 10\% replacements for fine aggregate all over the world, which leads to disposal of 80 million tones of plastic waste as a useful cost effective product. Of maximum usage of plastic waste (40\% approximately) and agro waste (Both RHA and SF-30\% approximately) without affecting the strength parameters of IS code Provisions, leads to reduction in cost of concrete by approximately $10 \%$ and it's a path for sustainable development and a durable one.

\section{Conclusion}

The following conclusions were made from the previous investigation carried out in the study.

i. The recycling of plastic will also yield several harmful by-products, which are very difficult to dispose. Hence, using these plastic wastes in concrete will be a definite solution to the problem of plastic waste disposal.

ii. Incorporation of plastic can lower the density of resulting concrete. Studies indicate that concrete containing various types of plastic aggregate meets the various national standards for lightweight concrete.

iii. Use of waste plastic in concrete can improve its toughness behaviour and therefore this type of concrete can absorb high amounts of energy, which has several practical implications. Combining the improvement of concrete toughness with the lightweight nature of plastic aggregate-based concrete, it can be envisaged that a lightweight plastic based concrete composite can be developed for earthquake resistance building construction.

iv. Previous results shows that the addition of plastic waste as aggregate in concrete up to a certain level can improve the abrasion resistance of concrete, which has several practical applications such as concrete paving blocks and hydraulic structures.

v. Though the cost of construction is cheaper along with the addition of RHA and SF which produce the impregnated concrete which can be used as an aggressive environment for its resistance against the aggressive environment.

vi. Due to rich in silica content and pozzolanic properties, the RHA and SF enhance the strength; also it had closely packing of micro structure in nature which reduces the permeability of concrete leads to increase in durability of concrete.

vii. The plastic waste has the smooth surface, which is the main reason for the reduction in both the compressive strength and the tensile strength of the concrete.

\section{References}

[1] Prasanna K. Acharya and Sanjaya K. Patro. 2016. Acid resistance, sulphate resistance and strength properties of concrete containing ferrochrome ash (FA) and lime. Construction and building materials, 12 May 2016, 241-250.

[2] M. Albitar, M.S. Mohamed Ali, P. Visintin and M. Drechsler. 2017. Durability evaluation of geopolymer and conventional concretes. Construction and Building Materials, 17 January 2017, $374-385$.

[3] B. Chatveera and P. Lertwattanaruk. 2010. Durability of conventional concretes containing black rice husk ash. Journal of Environmental Management, 7 August 2010, 59-66.

[4] Anhad Singh Gill and Rafat Siddique. 2018. Durability properties of self-compacting concrete incorporating metakaolin and rice husk ash. Construction and Building Materials, 6 May 2018, 323 - 332.

[5] V. Ramasamy. 2011. Compressive Strength and Durability Properties of Rice Husk Ash Concrete, KSCE Journal of Civil Engineering, 4 April, 2011, 93 - 102.

[7] M. Vigneshwari, K. Arunachalam and A. Angayarkanni. 2018. Replacement of silica fume with thermally treated rice husk ash in Reactive Powder Concrete. Journal of Cleaner Production, 3 April 2018, 264 - 277.

[8] R.V. Silva, J. de Brito and Nabajyoti Saikia. 2012. Influence of curing conditions on the durability-related performance of concrete made with selected plastic waste aggregates, 28 August 2012, 23 - 31 .

[10] B.V.Bahoria, D.K.Parbat and P.B.Nagarnaik. 2016. XRD Analysis of Natural sand, Quarry dust, waste plastic (ldpe) to be used as a fine aggregate in concrete, 30 July, 2016, $1432-1438$.

[11] Uchechi G. Eziefula, John C. Ezeh and Bennett I. Eziefula. 2018. Properties of seashell aggregate concrete: A review. Construction and Building Materials, 15 October 2018, 287-300.

[12] Ehsan Mohseni, Mohammad Ali Yazdi, Bahareh Mehdizadeh Miyandehi, Mehdi Zadshir and Malek Mohammad Ranjbar. 2017. Combined Effects of Metakaolin, Rice Husk Ash, and Polypropylene Fiber on 
the Engineering Properties and Microstructure of Mortar. American Society of Civil Engineers, 23 March 2017.

[13] A. Muthadhi and S. Kothandaraman. 2013. Experimental Investigations of Performance Characteristics of Rice Husk Ash-Blended Concrete. American Society of Civil Engineers, 18 May 2015.

[14] Safwan A. Khedr and Mohamed Nagib Abou-Zeid. 2014. Characteristics of silica-fume concrete. American Society of Civil Engineers, 02 July 2014.

[15] Fahad K. Alqahtani, M. Iqbal Khan, Gurmel Ghataora and Samir Dirar. 2016. Production of Recycled Plastic Aggregates and Its Utilization in Concrete. American Society of Civil Engineers, 30 October 2016.

[16] Ehsan Yaghoubi, Arul Arulrajah, Yat Choy Wong and Suksun Horpibulsuk. 2018. Stiffness Properties of Recycled Concrete Aggregate with Polyethylene Plastic Granules in Unbound Pavement Applications. American Society of Civil Engineers, 19 March 2018.

[17] F.S. Khalid, J.M. Irwan, M.H. Wan Ibrahim, N. Othman and S. Shahidan. 2018. Performance of plastic wastes in fiber-reinforced concrete beams. Construction and Building Materials, 10 June 2018, 451-464.

[18] Ravande kishore, V.Bhikshma and P.Jeevana prakash. 2011. Study on Strength Characteristics of High Strength Rice Husk Ash Concrete. The Twelfth East Asia-Pacific Conference on Structural Engineering and Construction, Proceedia Engineering, 2666-2672.

[19] Samuel Kofi Tulashie, Francis Kotoka, David Mensah, Anthony Kwame Kwablah. 2017. Investigation of the compressive strength of pit sand, and sea sand mortar prisms produced with rice husk ash as additive. Construction and Building Materials, 15 June 2017, 383-387.

[20] Riccardo Maddalena and Andrea Hamilton. 2017. Low-pressure silica injection for porosity reduction in cementitious materials. Construction and Building Materials, 610-616.

[21] Brahim Safi, Mohammed Saidi, Djamila Aboutaleb and Madani Maallem. 2013. The use of plastic waste as fine aggregate in the self-compacting mortars: Effect on physical and mechanical properties. Construction and Building Materials, 26 February 2013, 436-442.

[22] Rafat Siddique, Jamal Khatib and Inderpreet Kaur. 2007. Use of recycled plastic in concrete: A review. Waste Management, 15 September 2007, 1835-1852.

[23] A. Muthadhi and S. Kothandaraman. 2013. Experimental Investigations of Performance Characteristics of Rice Husk Ash-Blended Concrete. American Society of Civil Engineers.

[24] Nabajyoti Saikia and Jorge de Brito. 2012. Use of plastic waste as aggregate in cement mortar and concrete preparation: A review. Construction and Building Materials, 5 April 2012, 385 - 401. 